\title{
Coping, Perceived Stress, Eating Behaviours, and Sleep Patterns (CoPES) of Undergraduate Nursing Students While in Practicum
}

\author{
By Efrosini A. Papaconstantinou* \\ Sue Coffey ${ }^{\prime}$ \\ Hilde Zitzelsbergert \\ Leslie Graham $^{+}$ \\ Evelyn Moreau \\ Mark McPherson ${ }^{\bullet}$
}

\begin{abstract}
Clinical education experiences are an integral component of undergraduate nursing education, typically involving high stress. Higher perceived stress levels are associated with poor sleep quality, anxiety and depressive symptoms, concentration difficulties, and disordered eating. This study explored the coping mechanisms, perceived stress, eating behaviours, and sleep characteristics of 24 th year undergraduate nursing students. Data was collected through an online questionnaire, which included four published scales related to coping, perceived stress, and sleep. Participants also responded to demographic questions and open-ended questions focused on sleep, stress, coping, and eating. There was a wide variation in perceived stress among students. Perceived stress, coping strategies, and eating habits appear to be closely related. Poor coping strategies increased the likelihood of being stressed, and participants with high stress were more likely to have poor eating habits. Sleep was a significant issue for most participants. Although the smaller sample size limits generalizability of the findings, results indicate further study is warranted.
\end{abstract}

Keywords: Coping, Eating patterns, Nursing students, Sleep, Stress

\section{Introduction}

Clinical education experiences are an integral component of undergraduate nursing and other health professions educational programs. The majority of clinical education experiences in undergraduate nursing in Ontario, Canada typically involve students attending clinical placements on weekdays (between Monday and Friday) for morning or afternoon shifts. Few nursing or other health professions students experience shift work and full-time practicum hours until they are in their final year of their program of study. Although the

\footnotetext{
* Assistant Professor, Faculty of Health Sciences, University of Ontario Institute of Technology Canada.

$\uparrow$ Associate Professor, Faculty of Health Sciences, University of Ontario Institute of Technology, Canada.

* Assistant Professor, Faculty of Health Sciences, University of Ontario Institute of Technology, Canada.

${ }^{+}$Professor, School of Health and Community Services, Durham College, Canada.

- Program and Practicum Co-ordinator, Medical Laboratory Science, University of Ontario Institute of Technology, Canada.

- Senior Analyst and Program Lead, Health System Research, Canada.
} 
benefits of clinical practice provide students the opportunity to apply knowledge as well as develop skills in their respective field of study, clinical practice can also be a great source of stress (Alzayyat and Al-Gamal 2014, Chesser-Smyth 2005, Gibbons et al. 2011). Challenges in making the transition from student to health care professional have been well documented and include lack of confidence and/or competence, fear of making mistakes, increased responsibility, role ambiguity, role overload encountering new situations, and adjusting to unit environments and procedures for the first time (Chang and Hancock 2003, Delaney 2003, Oermann and Garvin 2002, Wallace et al. 2015).

Higher perceived stress levels have been associated with poor sleep quality, anxiety and depressive symptoms, irritability, attention and concentration difficulties, poor academic performance, and disordered eating (Angelone et al. 2011, Charles et al. 2011, Lemma et al. 2012, Soukup et al. 1990). Anecdotal data suggests that students whose programs include a fulltime practicum component may be more prone to stress than other students. Stress experienced on the night before clinical experiences reduces the students' ability to sleep, therefore decreases their sleep duration (Chernomas and Shapiro 2013). This situation is particularly concerning for students in practicum since insufficient sleep can affect cognitive functioning and negatively interfere with daytime activities, increasing the risks for errors and potentially decreasing patient safety (McMillan and Edwards 2013, Mukanata et al. 2001). In contemporary healthcare, patient safety, defined as "reducing the risk of unnecessary harm" (World Health Organization 2010), increasingly has become a prime concern to promote optimal patient outcomes. Patient safety may be focused on primarily through "the reduction and mitigation of unsafe acts" (Vaismoradi et al. 2011: 435). In the context of the scope and complexity of patient safety, students are required to gain and demonstrate increasing skill and competency as they progress within clinical settings in order to develop proficient levels of quality of care needed for job readiness (Duhn et al. 2012). Thus, attention to the effects of stress on student performance and safety is critical.

Balancing academic demands with clinical practicum experiences has also been described as stressful (Chan et al. 2009, Gibbons et al. 2007, 2011). Nursing students have large amounts of preparatory work to complete prior to practicum assignments, contributing to their perception of stress in the clinical learning environment (Shipton 2002). They must also often travel long distances to clinical sites (Coffey et al. 2013) and use highly technical equipment, sometimes for the first time. The combination of working full or part time in addition to completing the equivalent of full-time clinical hours and also completing final academic requirements is also a significant source of stress for many final year nursing students, with feelings of exhaustion on their days off and having difficulty finding time to complete their assignments (Coffey et. al. 2016, Nolan and Ryan 2008). New graduates often describe experiencing difficulties in feeling relaxed during off duty time and therefore may not have the opportunities to deal with their work-related stress (Kapborg 
and Fischbein 1998). Additionally, individuals develop habitual ways of dealing with stress and these coping styles, whether positive or negative, can influence their reactions (Carver and Scheier 1994, Gibbons et al. 2011).

Given the important implications of perceived stress and how it relates to coping mechanisms, eating behaviors, and sleep disturbances in undergraduate nursing students in practicum experiences, targeted interventions are warranted. However, before targeted interventions can be developed and tested with rigorous evaluative methods, an important first step is to create a snapshot of these patterns to gain insight into how they may interrelate.

\section{Study Aims}

To that end, the aim of this study was to explore the coping mechanisms, perceived stress, eating behaviours, and sleep characteristics of $4^{\text {th }}$ year undergraduate nursing (Bachelor of Science in Nursing $(\mathrm{BScN})$ and Registered Practical Nurse to Bachelor of Science in Nursing (RPN-to-BScN)) students in their final year practicum placements. Additionally, this study explored predictors and relationships of coping, perceived stress, and sleep.

\section{Methods}

\section{Ethical Considerations}

Prior to commencing this study, research ethics board approval was obtained.

Design

This study was a descriptive, cross-sectional, mixed method design using an electronic survey.

\section{Sample and Setting}

The study took place at a university located in the east end of the Greater Toronto Area (GTA) in Canada. This university offers a four-year Bachelor of Science in Nursing (BScN) program and a post-diploma BScN program (RPNto-BScN) for those who have successfully completed a Registered Practical Nursing (RPN) diploma. Regardless of which path to the $\mathrm{BScN}$ (BScN or RPN-to-BScN), students are required to complete upper year practicum experiences to be eligible to earn their degree and write the registration exam for nurses in Ontario. The final practicum course consists of 420 mandatory clinical hours in which students work at a clinical site directly with a preceptor, following their preceptors' work shifts. Additionally, there are academic requirements tied to this course, including a learning plan, bi-weekly clinical 
updates, and a case study assignment. Concurrently, students must begin studying to pass the national registration exam, required in order to earn the designation of Registered Nurse upon completion of their educational program.

All year four nursing students enrolled in their final Professional Integrated Practicum course (NURS4701) during the winter term of 2015 were invited to participate in a survey focusing on sleep, perceived stress, coping, eating patterns, and demographics/life context. The invitation letter included a link to a secure on-line survey to be completed in LimeSurvey ${ }^{\mathrm{TM}}$, an online survey repository housed in Canada, where informed consent was obtained. Three reminder e-mails were sent to potential participants should they choose to take part in data collection. The on-line questionnaire took approximately 30 minutes to complete and was done at the participants' convenience. Out of a possible 102 eligible students, a total of 35 participants completed the questionnaire (27 $\mathrm{BScN}$ and $8 \mathrm{RPN}$-to-BScN). The survey did not have a forced completion feature, thus allowing participants to complete only those sections to which they chose to respond. As a result, of the participants who completed questionnaires, 11 elected to provide only partial data. The results presented in this paper represent the full data sets for the 24 complete questionnaire responses, representing $24 \%$ of the population of students invited to participate.

\section{Tools}

The questionnaire consisted of four published scales related to coping, perceived stress, and sleep:

\section{The Brief COPE (Carver 1997)}

This scale is a shortened item version of the COPE Inventory that was developed to assess a broad range of coping responses (Carver 1997). This scale is comprised of 14 subscales with two items in each, for a total of 28 items, that are rated by a four-point Likert scale, ranging from "I haven't been doing this at all" (score one) to "I have been doing this a lot" (score four). Items capture both functional and dysfunctional coping responses that include active coping, planning, positive reframing, acceptance, humor, religion, using emotional support, using instrumental support, selfdistraction, denial, venting, substance use, behavioral disengagement, and self-blame. Internal reliabilities for the 14 subscales range from $\alpha=0.57$ 0.90 (Carver 1997).

\section{The Perceived Stress Scale (PSS) (Cohen et al. 1983)}

The PSS is a psychological instrument that measures the degree to which situations in one's life are appraised as stressful. The 10 items on the PSS assess the degree to which respondents perceive situations as unpredictable or uncontrollable, or the degree to which they perceive an overload of difficulties. It has been correlated with life-event scores, depressive and physical symptomology, utilization of health services, and social anxiety 
(Cohen et al. 1983). The PSS demonstrates good reliability as the Cronbach's alpha was evaluated at $>0.70$ in a study which reviewed 12 studies in which the PSS-10 was used (Lee 2012).

\section{The Pittsburgh Sleep Quality Index (PSQI) (Buysse et al. 1989)}

The PSQI is a 19-item self-rated questionnaire with seven components that evaluate sleep behaviours over a one month period (Buysse et al. 1989). The components include: Sleep Quality (i.e., self-perception of one's sleep quality), Sleep Latency (i.e., time it usually takes to fall asleep at night), Sleep Duration (i.e., average hours of actual sleep nightly), Habitual Sleep Efficiency (i.e., actual hours of sleep compared to hours spent in bed), Sleep Disturbances (i.e., factors that cause wakening during the night or early morning), Sleeping Medication Use (i.e., over the counter or prescribed), and Daytime Dysfunction (i.e., difficulty staying awake during the day). Each scale is weighted equally, with score ranges from 0 to 3. Together, these component scores are summed to provide a global score with a cut off of $>5$ indicative of a poor-quality sleeper. Psychometric testing of the PSQI demonstrates good internal consistency and construct validity in men and women of various populations (Beck et al. 2004, Buysse et al. 1989, Carpenter and Andrykowski 1998). As well, it is a reliable instrument for use with college students, with Cronbach's alpha $=0.73$ (Lund et al. 2010).

\section{The Epworth Sleepiness Scale (ESS) (Johns 1991)}

The ESS is an eight item questionnaire that measures excessive daytime sleepiness that is associated with accumulated sleep debt (Johns 1991). The ESS asks individuals to rate their usual chance of falling asleep in different situations. Based on a four-point scale (0-3) the total ESS score is the sum of all eight items and can range between 0 and 24. A higher score indicates a higher degree of daytime sleepiness, with scores greater than 10 indicating significant levels of daytime sleepiness. A recent systematic review evaluating the psychometric properties of the ESS found good internal consistency by Cronbach's alpha values (0.73-0.86) (Kendzerska et al. 2014).

Additionally, participants were asked to respond to a range of questions focusing on demographics and the context of their lives during this period, as well as some basic questions about eating patterns and attitudes toward eating. Finally, an open-ended qualitative question asked participants to share any comments about sleep, stress, coping, and eating not included in the questionnaire.

\section{Data Management and Statistical Analyses}

Quantitative data were downloaded from LimeSurvey ${ }^{\mathrm{TM}}$ and imported to Microsoft Excel (Microsoft Corp 2010) and then analyzed using SAS (SAS 
Corp 2013). Results are presented as frequencies and means, and the Type I error rate was set a 0.05 for statistical significance. Means between study programs were compared using two sample t-tests and proportions were compared using chi-square tests. Backwards elimination linear regression was used to determine factors associated with stress, coping strategies, and sleep patterns.

\section{Results}

\section{Demographics}

Of the 24 completed surveys, the overwhelming majority (56\%) of participants were between the ages of 19-24 and female (83\%) (Table 1). This finding is consistent with typical age and gender distributions for undergraduate nursing students in this jurisdiction and consistent over time for the duration of this program (Coffey et al. 2013). The 11 participants who did not complete all components of the survey and consequently were excluded from the remainder of the analyses did not statistically differ from the participants who completed the study with respect to age, gender, or ethnicity (p-value >0.05).

Table 1. Participant Demographics

\begin{tabular}{|c|c|c|c|}
\hline Demographic & Category & $\mathrm{N}=24$ & $\%$ \\
\hline \multirow{4}{*}{ Age } & $19-24$ & 14 & $58 \%$ \\
\hline & $25-29$ & 5 & $21 \%$ \\
\hline & $30+$ & 4 & $17 \%$ \\
\hline & missing & 1 & $4 \%$ \\
\hline \multirow[t]{2}{*}{ Gender } & Female & 21 & $87 \%$ \\
\hline & Male & 3 & $13 \%$ \\
\hline \multirow[t]{2}{*}{ Ethnicity } & Caucasian & 12 & $50 \%$ \\
\hline & Other & 12 & $50 \%$ \\
\hline \multirow{3}{*}{$\begin{array}{l}\text { Previous } \\
\text { Education }\end{array}$} & High School & 9 & $38 \%$ \\
\hline & Some College & 9 & $38 \%$ \\
\hline & Some University & 6 & $25 \%$ \\
\hline \multirow[t]{2}{*}{ Marital Status } & Married & 5 & $21 \%$ \\
\hline & Unmarried & 19 & $79 \%$ \\
\hline \multirow[t]{2}{*}{ Children } & Has Children & 4 & $13 \%$ \\
\hline & No children & 20 & $87 \%$ \\
\hline \multirow[t]{2}{*}{ Support } & Supports Family & 6 & $25 \%$ \\
\hline & Does not support family & 18 & $75 \%$ \\
\hline \multirow[t]{2}{*}{$\begin{array}{l}\text { Post-secondary } \\
\text { family history }\end{array}$} & $\begin{array}{l}\text { First person to attend post-secondary } \\
\text { education from family }\end{array}$ & 5 & $21 \%$ \\
\hline & Not first person to attend & 19 & $79 \%$ \\
\hline \multirow[t]{2}{*}{ Employment } & Worked while attending school & 20 & $83 \%$ \\
\hline & Did not work while attending school & 4 & $17 \%$ \\
\hline
\end{tabular}


The overwhelming majority (typically $>75 \%$ ) of nursing students in their final practicum experience complete 12 hour shifts. Adding additional commuting time prior to and following the shift, and the necessary on site preparation time required before the shift begins may mean a 12 hour day or night shift easily becomes 13,14 , or even 15 hours from the point of leaving home to the point at which one returns. It is not surprising then, that travel to and from campus and practicum has been shown to be a significant issue for nursing students who are undertaking practicum experiences and coursework (Coffey et al. 2016, 2013). For that reason, participants were asked about their mode of commuting (e.g., public transportation or private vehicle) and the time it took to commute to practicum and to campus for classes. Many respondents used a variety of commuting strategies (e.g., public transit as well as car or taxi). However, the majority of students commuted to campus $(63 \%)$ and to their practicum placement $(83 \%)$ using a car at least some of the time (Table 2 ). The wide range of locations for practicum placements and the off-hour start and finish of long shifts students experience in their practicum placements are two likely explanations for the increased use of a car rather than relying on public transit alone for travel to practicum experiences. Commute times were generally between 30-50 minutes, but varied based on program and destination (campus vs practicum). Average commute time to practicum placements was slightly longer than commute time to campus (38 min vs $31 \mathrm{~min}$ ) with wide variation between participant commute times to both locations.

Table 2. Commute Strategies and Times for Participants

\begin{tabular}{|l|c|}
\hline & Participants (N=24) \\
N (\%) \\
\hline To Campus \\
\hline Method of Commute* \\
\hline Car & $15(63 \%)$ \\
\hline Public Transit & $15(63 \%)$ \\
\hline Other (e.g., walking and/or biking) & $3(13 \%)$ \\
\hline Average Commute Time (mins) & $31 \mathrm{~min}$ \\
\hline Commute Time Range & 0 min-70 min \\
\hline To Practicum & \\
\hline Method of Commute* & $20(83 \%)$ \\
\hline Car & $11(46 \%)$ \\
\hline Public Transit & $2(8 \%)$ \\
\hline Other (e.g., walking and/or biking) & $38 \mathrm{~min}$ \\
\hline Average Commute Time (mins) & $10 \mathrm{~min}-120 \mathrm{~min}$ \\
\hline Commute Time Range &
\end{tabular}

Notes: Data are presented as frequency (percentage) for categorical variables or means $( \pm$ standard deviation) for continuous variables.

* Percentages do not add up to $100 \%$ because participants could select more than one means of commuting. 


\section{Perceived Stress, Coping Strategies, and Eating Habits}

Participants' responses indicated varying levels of perceived stress amongst study participants. Three-quarters of participants $(75 \%)$ reported feeling nervous or stressed in the last month, while half $(50 \%)$ felt that difficulties were piling up so high that they could not overcome them. At the same time, close to half $(46 \%)$ felt confident in their ability to handle personal problems, and fully half (50\%) felt things were going their way (Table 3 ). This variation in response pattern is important to further consider in terms of life, learning, and practicum conditions that may have an impact on perceived stress.

Table 3. Perceived Stress

\begin{tabular}{|l|c|}
\hline PSS Variable & N (\%) \\
\hline Upset as a result of unexpected outcome & $11(46 \%)$ \\
\hline Unable to control the important things in life & $9(38 \%)$ \\
\hline Feelings of nervousness or stress & $18(75 \%)$ \\
\hline Felt confident about ability to handle personal problems & $11(46 \%)$ \\
\hline Felt things were going your way & $12(50 \%)$ \\
\hline Not able to cope with all the things that had to do & $10(42 \%)$ \\
\hline Ability to control irritations in life & $9(38 \%)$ \\
\hline Felt that you were on top of things & $9(38 \%)$ \\
\hline Been angered because of things that were outside control? & $10(42 \%)$ \\
\hline Felt difficulties piling up so high that you could not overcome them & $12(50 \%)$ \\
\hline
\end{tabular}

With higher scores indicating poorer coping, students had a mean of 66 $( \pm 7.0)$ out of a possible score of 112 on the Brief COPE. The majority of participants indicated that coping strategies included getting emotional support from others (48\%), getting advice from other people (48\%), and turning to work or other activities to take their mind off of things $(60 \%)$. Fewer utilized alcohol or drugs (12\%) to make them feel better or gave up trying to feel better $(20 \%)$. Over half reported taking actions to make the situation better $(57 \%)$.

Shift work clearly impacted eating behaviours, with $64 \%$ of respondents indicating that they ate more junk food while on shift. Seventy-two percent found it hard to watch what they ate and only about half (48\%) reported feeling good about how they look. Of interest, four out of five students $(80 \%)$ said they would feel better about themselves if they could change their weight.

Few individuals $(\mathrm{N}=6)$ fell within the bottom quartile for perceived stress, coping strategies, and eating habits. However, these three dimensions did appear to be closely related with participants who exhibited poor coping strategies (below the median). These students had five times the likelihood of being stressed $(\mathrm{OR}=4.9, \mathrm{p}=0.02)$. In turn, those with high stress were also more likely to have poor eating habits during their practicum experience $(\mathrm{OR}=11$, $\mathrm{p}=0.001$ ). Regression analyses indicated that being younger, unmarried, and having no previous education increased the probability of poor coping strategies (Table 4). There were no statistically significant predictors of high stress levels or poor eating habits. 
Table 4. Predictors of Poor Coping Strategies, High Stress Levels and Poor Eating Habits after Backwards Elimination of Variables not Shown to be Statistically Significant*

\begin{tabular}{|c|c|c|}
\hline Predictor & p-value & Beta \\
\hline \multicolumn{3}{|l|}{ Poor Coping Strategies } \\
\hline Age & 0.02 & -0.9 \\
\hline Previous Education & 0.04 & 3.7 \\
\hline Marital Status & 0.01 & -7.8 \\
\hline \multicolumn{3}{|l|}{ High Stress Levels } \\
\hline (None) & N/A & N/A \\
\hline \multicolumn{3}{|l|}{ Poor Eating Habits } \\
\hline (None) & N/A & N/A \\
\hline
\end{tabular}

Note: $* \mathrm{p}<0.1$

\section{Sleeping Patterns}

Amongst the nursing students, very few participants reported experiencing good sleep quality (Table 5). The median bed time was 23:00. Students averaged 5.8 hours of sleep and it took over 30 minutes on average for students to fall asleep. Nearly two-fifths of participants (39\%) had high levels of daytime sleepiness. As well, over half (57)\% of participants reported that there was a high chance of them falling asleep while sitting and reading and a similar proportion $(58 \%)$ indicated that there was a high chance of them falling asleep while watching TV. Over half (53\%) of participants reported that there was a high chance of them falling asleep while in a car (as a passenger).

Table 5. Sleep Quality and Daytime Sleepiness

\begin{tabular}{|l|c|}
\hline & Participants (N=24)* \\
\hline Good Sleep Quality (PSQI $\leq 5)(\%)$ & $2(8 \%)$ \\
\hline Median Bed Time (range) & $23: 00(21: 00-0: 200)$ \\
\hline Median Awake Time (range) & $05: 30(04: 00-07: 00)$ \\
\hline Mean Hours of Sleep $( \pm$ SD) & $5.8( \pm 1.7)$ \\
\hline Mean Minutes to Fall Asleep ( \pm SD) & $36.5( \pm 28.8)$ \\
\hline ESS Sleepiness score & $12.5( \pm 3.9)$ \\
\hline Significant daytime sleepiness $($ ESS score $>10)(\%)$ & $16(67 \%)$ \\
\hline
\end{tabular}

Note: * Data are presented as frequency (percentage) for categorical variables or means $( \pm$ standard deviation) for continuous variables.

Regression analyses indicated three statistically significant predictors of poor sleep quality: poor eating habits $(\mathrm{p}=0.04)$, working $(\mathrm{p}=0.02)$, and younger age $(\mathrm{p}=0.02)$. Race $(\mathrm{p}=0.07)$ and being married $(\mathrm{p}=0.06)$ approached statistical significance (Table 6). Factors that were not shown to be statistically associated with sleeping quality included commute time, coping strategies, and gender. The $\mathrm{R}$-squared of the model after elimination of these variables was 0.09 . 
Table 6. Predictors of Poor Sleep Quality after Backwards Elimination of Variables not Shown to be Statistically Significant*

\begin{tabular}{|l|c|c|}
\hline Predictor & p-value & Beta \\
\hline Poor Eating Habits & 0.04 & 0.02 \\
\hline Working & 0.02 & 0.08 \\
\hline Age & 0.02 & -0.001 \\
\hline Married** & 0.06 & -0.003 \\
\hline Race** & 0.07 & 0.08 \\
\hline
\end{tabular}

Note: $\quad * * \mathrm{p}<0.1$

** approaching statistical significance.

Comments about Coping, Stress, Eating, and Sleep

Final, open-ended qualitative questions were included in this online questionnaire. Thematic analysis of written responses to these questions was undertaken using NVIVO10. Participants were invited to include any comments they would like to express about their coping, stress, eating habits, and sleep in relation to their final practicum experience. Three themes of time challenges, sleep challenges, and the need for necessary supports were identified.

\section{Time Challenges}

Time was an important element in the experience of final practicum for many participants. For some students, time constraints and multiple obligations on one's time led to financial difficulty due to the need to both work and complete their practicum hours:

"Working full-time hours in placement decreased the amount of time I have had to work at my part time job, which caused much stress due to lack of financial stability."

For other students, time constraints led to challenges in maintaining personal health and a healthy lifestyle while trying to complete the 420 required hours of clinical time:

"Being out in placement while still going to school, having time for family, grocery shopping, making dinner and lunches, and every day activities, while trying to go to the gym, or clean the house is absolutely exhausting ... students [need] a chance to study and do everything else they must do in their lives to keep themselves happy and healthy."

\section{Sleep Challenges}

Sleep insufficiency and challenges associated with sleep were also noted in the comments. Although students recognize the importance of sleep, there were so many other competing demands on time that sleep was not a priority: 
"Sleeping is crucial for students, but we don't have enough time due to our weekly assignments etc. and studying for the NCLEX."

The difficulty with sleep initiation with rotating shifts was also noted:

"I cannot fall asleep without melatonin or Nyquil. My body aches and I am sleepy every single minute of the day."

Need for Necessary Supports

Some students commented about resources for coping and found friends, especially those within the same program, to be helpful. Others felt the need for more formal debriefing sessions and other coping mechanisms:

"Friends are an extremely large part of keeping [me] sane especially those who are in your program going through the same thing. Group study sessions are a must, even if no talking is happening. Silence is golden as long as you're with someone."

"It is a very difficult transition for students who have done nothing but school for the last 17 years of life (coming direct from high school). Need debriefing sessions at the school for 4th year. There is a mental component for placement and graduation. Need support groups and mentoring sessions, as we see so much but do not have access to appropriate coping mechanisms."

\section{Discussion}

Stress in nursing students is an area of growing concern. Fully three quarters of the participants in this sample $(75 \%)$ reported feeling nervous or stressed during their final practicum experience. While this may not be an unexpected finding given the rigorous academic and professional demands placed on students when they begin to take responsibility for patient care, it remains highly concerning.

Overall participants' responses indicated a high level of stress, with $75 \%$ of participants reporting feeling stressed in the last month. An equal number of participants $(50 \%)$ felt that difficulties were piling up so high that they could not overcome them compared to participants $(50 \%)$ who felt that things were going their way. This apparent dichotomization of either seeing the glass half full or seeing it half empty, despite widespread experience of stress, is a phenomenon that deserves further exploration. The impact that stress has on student learning and performance has been highlighted in literature (Alzayyat and Al-Gamal 2014, Wallace et al. 2015). Understanding how students in stressful situations process that experience and make sense of it may then be an important step in providing necessary supports and potential educational 
offerings to mitigate the stress experience for nursing students in practicum (Gibbons et al. 2011). For example, nearly half (46\%) of the participants felt confident in their ability to handle personal problems. Coping strategies that were most often used were getting emotional support and advice from others and using work to take their mind off of things. It appears that peer support is a positive coping strategy and should be considered when developing interventions for nursing students entering their final practicum experience.

Participants with higher perceived stress were also more likely to have poor eating habits during their practicum experience. Stress has been associated with eating patterns in that stress may lead to poor food choices, often for preferences for foods high in sugar and fat (Barrington et al. 2014). Shift work impacted students' eating patterns, as 64\% reported that they ate more junk food while on shift and $72 \%$ found it difficult to watch what they ate. Consuming more junk food among nursing students has been a consistent finding in other studies (Evagelou et al. 2014, Sharma et al. 2009). Potential factors contributing to these phenomena may include fewer eating opportunities during a long and often busy shift, limited healthy options available for consumption at practicum placements, particularly during offhour shifts such as overnight, and the impact of perceived time constraints on food preparation.

Statistical analysis identified a relationship between perceived stress, coping strategies, and eating habits for participants who exhibited poor coping strategies (below the median). With a finding that students in this category had five times the likelihood of being stressed $(\mathrm{OR}=4.9, \mathrm{p}=0.02)$, attention to supporting students to develop and implement positive coping strategies prior to and during their final practicum experience is important. This focus will now be included in the pre-practicum orientation sessions going forward. Additionally, appreciating that students with high stress were more likely to have poor eating habits during their practicum experience enables faculty to prepare students for the reality of life during their practicum. One approach to be piloted in the winter of 2017 will be the inclusion of a Registered Dietician to provide an interesting and informative session on "healthy eating on the run" as a pre-practicum workshop.

Sleep was identified as a significant concern for participants. Students were severely sleep restricted, averaging only 5.8 hours of sleep. This amount is less than the recommended seven to nine hours according to the National Sleep Foundation (Hirshkowitz et al. 2015). Students pursuing post-secondary education are a population group that is increasingly recognized to be at risk for significant sleep problems (Garlow et al. 2008, Regestein et al. 2010). Sleep deprivation, resulting in daytime sleepiness, is highly prevalent among college students with as many as 50\% reporting daytime sleepiness and $70 \%$ attaining insufficient sleep (Hershner and Chervin 2014). In the current study, only 8\% of students were found to be good quality sleepers and a higher proportion of BScN Collaborative students $(40.7 \%)$ reported significant daytime sleepiness as compared to the RPN-to-BScN program students (38\%). This is particularly concerning as consequences of sleep restriction have a direct bearing on 
students' ability to provide safe, competent patient care. The literature reveals that for experienced nurses, being sleep deprived (defined as obtaining less than 5 hours of continuous sleep) leads to greater likelihood of making patient care errors (Johnson et al. 2004) or catching someone else's error (Dorrian et al. 2006). Sleep deprived nurses are also at increased risk of making an error when work shifts that are extended longer than twelve hours, when they work overtime, or when they work more than 40 hours per week (Rogers et al. 2004). This data is alarming when we consider then the potential risk to patient safety with sleep deprived student nurses. While student nurses experience all of the same risk factors as experienced nurses (sleep restriction, working long shifts with additional extended commute times, and working more than 40 hours per week with the addition of part-time jobs), they do not have the practice background and workplace familiarity to mitigate these risks.

Through regression analysis, a model was identified in which five variables (poor eating habits, younger age, race, being married, and working while completing the practicum) accounted for $9 \%$ of the variation in sleep quality. This finding is highly informative in terms of critical counselling and preparation prior to this final practicum experience that may support students more comprehensively. While students are currently advised that undertaking paid employment concurrent to the full-time clinical hours required in this practicum is not advisable, sharing the impact that this practice may have on their ability to attain quality sleep will potentially be important in enabling students to make a more informed choice about whether they can cut back on working hours or not work at all. Additionally, it may help students to choose to prioritize sleep needs in a more informed manner. Similarly, understanding the possible connection between poor eating habits and sleep quality may support students to create conditions, where possible, in which healthy lifestyle choices become a higher priority. While age, race, and marital status may be considered non-modifiable factors (or factors not wisely modifiable just for the sake of this one final practicum in the case of marital status), insights gained from this study enable faculty to more effectively prepare students for challenges they may experience in their final practicum.

Future studies examining sleep patterns in nursing students working different 12-hour shifts should include both subjective measures (e.g., PSQI) and objective measures of sleep such as actigraphy. An actigraph is a device worn comfortably around the wrist and records movements that can be used to estimate sleep parameters with specialized algorithms (Martin and Hakim 2011). Actigraphy allows participants to remain in their natural environments while reliably quantifying periods of wakefulness and sleep. Relationships between sleep patterns, sleep disturbances, chronotype, and daytime sleepiness can then be examined more objectively within this population.

Qualitative analysis of students' general comments related to stress, coping, sleep, and eating revealed themes of time challenges, sleep challenges, and the need for necessary supports. These findings highlight the difficulties students experience in completing their final practicum experience consisting of full-time clinical hours, on top of the need to study for a high stakes 
registration exam and maintain the responsibilities inherent in their personal lives. Participants in this study identified the need for supports such as friends, time shared with others, and support groups/mentoring as important. While beyond the scope of this study, it is imperative that further examination of the factors in the educational experience and life context of nursing students that impede or promote academic and clinical performance and support quality of life be undertaken. Furthermore, given the higher level of emphasis on patient safety currently taking place in nursing education (Duhn et al. 2012, Vaismoradi et al. 2011) identifying factors that help support educators to facilitate more supportive educational experiences, especially during final practicum, is vital to ensure students are able to more readily develop competent and safe practices, ensuring their job readiness.

Although this study has provided some insight into the coping, perceived stress, eating, and sleep characteristics of final year undergraduate student nurses in their final practicum placement, it is not without limitations. The relatively small sample size precludes generalization beyond the study population. The cross-sectional nature of this study only provides information about these characteristics at one point in time, whereas coping, stress, eating patterns, and sleep quality may be varied at different time points. It is recommended that future studies consider a longitudinal approach, examining student experiences during all years of an undergraduate nursing degree program.

\section{Conclusion}

The aim of this descriptive study was to assess the coping, perceived stress levels, eating behaviours, and sleep patterns of undergraduate nursing students in their final practicum experience. Students experienced high levels of perceived stress, and were sleep deprived. Targeted wellness interventions including self-care education about stress management and related skills for students to manage the rigors of post-secondary, professional education are warranted. In particular, support for students to develop effective coping strategies and sleep health education strategies are an essential component in this process. Faculty are in a unique position to support nursing students to help them develop adaptive coping mechanisms that they can implement during stressful situations, and thus, decreasing risks for errors and improving patient safety and quality of care. Future research should include a longitudinal methodology to gain more insight into the coping, stress, eating habits, and sleep patterns of students across different years. 


\section{Acknowledgments}

We wish thank all the students who took time to complete the study. We would also like to express our sincere gratitude to Holly McPherson for her administrative support throughout the study period.

\section{References}

Alzayyat A, Al-Gamal E (2014) A review of the literature regarding stress among nursing students during clinical education. International Nursing Review 16(3): 406-415.

Angelone AM, Mattei A, Sbarbati M, Di Orio F (2011) Prevalence and correlates for self-reported sleep problems among nursing students. Journal of Preventive Medicine and Hygiene 52(4): 201-208.

Barrington W, Beresford S, McGregor B, White E (2014) Perceived stress and eating behaviors by sex, obesity status, and stress vulnerability: Findings from teh Vitamins and Lifestyle (VITAL) study. Journal of the Academy of Nutrition and Dietetics 114(11): 1791-1799.

Beck SL, Schwartz AL, Towsley G, Dudley W, Barsevick A (2004) Psychometic evaluation of the Pittsburgh Sleep Quality Index in cancer patients. Journal of Pain and Symptoms Management 27: 140-8.

Buysse DJ, Reynolds CF, Monk TH, Berman SR, Kupfer DJ (1989) The Pittsburgh Sleep Quality Index (PSQI): A new instrument for psychiatric research and practice. Psychiatry Research 28(2): 193-213.

Carpenter J, Andrykowski M (1998) Psychometric evaluation of the Pittsburgh Sleep Quality Index. Journal of Psychosomatic Research 45(1): 5-13.

Carver CS (1997) You want to measure coping but your protocol's too long: Consider the Brief COPE. International Journal of Behavioral Medicine 4: 92-100.

Carver CS, Scheier MF (1994) Situational coping and coping dispositions in a stressful transaction. Journal of Personality and Social Psychology 66: 184-195.

Chan CKL, So WKW, Fong DYT (2009) Hong Kong baccalaureate nursing students' stress and their coping strategies in clinical practice. Journal of Professional Nursing 25(5): 307-313.

Chang E, Hancock K (2003) Role stress and role ambiguity in new nursing graduates in Australia. Nursing and Health Sciences 5: 155-163.

Charles LE, Slaven JE, Mnatsakanova A, Ma C, Violanti JM, Fekedulegn D, Burchfiel CM (2011) Association of perceived stress with sleep duration and sleep quality in police officers. Internationa Journal of Emergency Mental Health 13(4): 229241.

Chernomas WM, Shapiro C (2013) Stress, depression, and anxiety among undergraduate nursing students. International Journal of Nursing Education Scholarship 10(1): 255-266.

Chesser-Smyth P (2005) The lived experiences of general student nurses on their first clinical placement: a phenomenological study. Nurse Education in Practice 5(6): 320-327.

Coffey S, Lindsay G, Cochrane M, Cummings K, Macdonald K, Mairs S, Sproul S, Bouchard S, Lulat Z, Salamat N, Bell R (2016) Making the grade through the front door: Evaluation and innovation in a Registered Practical Nurse to Bachelor 
of Science in Nursing Program. Journal of Education and Training Studies 4(1): 32-38.

Coffey S, Lindsay G, Cochrane M, Cummings K, Macdonald K, Mairs S, Bouchard S, Lulat Z, Salamat N, Bell R (2013) Three-partner Collaborative evaluation of student transition, performance, experience, and outcomes in practical nursing Phase 3 Report. Submitted to ONCAT, January 2013.

Cohen S, Kamarck T, Mermelstein R (1983) A global measure of perceived stress. Journal of Health and Social Behavior 24: 386-396.

Delaney C (2003) Walking a fine line: Graduate nurses' transition experiences during orientation. Journal of Nursing Education 42(10): 437-443.

Dorrian J, Lamond N, van den Heuvel C, Pincombe J, Rogers A, Dawson D (2006) A pilot study of the safety implications of Australian Nurses' sleep and work hours. Chronobiology International 23(6): 1149-1163.

Duhn L, Karp S, Oni O, Edge D (2012) Perspectives on Patient Safety among undergraduate nursing students. Journal of Nursing Education 51(9): 526-531.

Evagelou E, Vlachou E, Polikandrioti M, Koutelekos I, Dousis E, Kyritsi E (2014) Exploration of nursing students' dietary habits. Health Science Journal 8(4): 452468.

Garlow S, Rosenberg J, Moore J (2008) Depression, desperation, and suicidal ideation in college students: results from the American Foundation for Suicide Prevention College Screening Project at Emory University. Depress Anxiety 25(6): 482-488.

Gibbons C, Dempster M, Moutray M (2011) Stress, coping and satisfaction in nursing students. Journal of Advanced Nursing 67(3): 621-632.

Gibbons C, Dempster M, Moutray M (2007) Stress and eustress in nursing students. Journal of Advanced Nursing 61(3): 282-290.

Hershner S, Chervin R (2014) Causes and consequences of sleepiness among college students. Nature and Science of Sleep 6: 73-84.

Hirshkowitz M, Whiton K, Albert S, Alessi C, Bruni O, DonCarlos L, Hillard P (2015) National Sleep Foundation's sleep time duration recommendations: methodology and results summary. Sleep Health 1: 40-43.

Johns MW (1991) A new method for measuring daytime sleepiness: the Epworth Sleepiness Scale. Sleep 14(6): 540-545.

Johnson A, Jung L, Brown K, Weaver M, Richards K (2004) Sleep deprivation and error in nurses who work the night shift. Journal of Nursing Administration 44(1): 17-22.

Kapborg ID, Fischbein S (1998) Nurse education and professional work: Transition problems? Nurse Education Today 18: 165-171.

Kendzerska TB, Smith PM, Brignardello-Petersen R, Leung RS, Tomlinson GA (2014) Evaluation of the measurement properties of the Epworth sleepiness scale: A systematic review. Sleep Medicine Reviews 18: 321-331.

Lee E-H (2012) Review of the Psychometric Evidence of the Perceived Stress Scale. Asian Nursing Research 6: 121-127.

Lemma S, Gelaye B, Berhane Y, Worku A, Williams M (2012) Sleep quality and its psychological correlates among university students in Ethiopia: a cross-sectional study. BMC Psychiatry 12(237).

Lund H, Reider B, Whiting A, Prichard J (2010) Sleep patterns and predictors of disturbed sleep in a large population of college students. Journal of Adolescent Health 46: 124-132.

Martin JL, Hakim AD (2011) Wrist Actigraphy. Chest 139(6): 1514-1527. 
McMillan D, Edwards M (2013) Assessment, contributing factors, and perceived consequences of sleep health in student nurses. Sleep 36(Abstract Supplement): A423.

Mukanata M, Ichii S, Nunokawa T, Saito Y, Ito N, Fukudo S, Yoshinaga K (2001) Influence of night shift work on psychologic state and cardiovascular and neuroendocrine responses in healthy nurses. Hypertension Research 24(1): 25-31.

Nolan G, Ryan D (2008) Experience of stress in psychiatric nursing students in Ireland. Nursing Standard 22(43): 35-43.

Oermann MH, Garvin MF (2002) Stresses and challenges for new graduates in hospitals. Nurse Education Today 22: 225-230.

Regestein Q, Natarajan V, Pavlova M, Kawasaki S, Gleason R, Koff E (2010) Sleep debt and depression in female college students. Psychiatry Research 176(1): 3439.

Rogers A, Wei-Ting H, Scott L, Aiken L (2004) The working hours of hospital staff nurses and patient safety. Health Affairs 23(4): 202-212.

Sharma S, Kaur J, Kaur J, Kaur J, Kaur K (2009) A descriptive study on dietary pattern and biophysical profie among ursing students. Nursing and Midwifery Research Journal 5(2): 80-88.

Shipton SP (2002) The process of seeking stress-care: Coping as experienced by senior baccalaureate nursing students in response to appraised clinical stress. Journal of Nursing Education 41(6): 243-256.

Soukup VM, Beiler ME, Terrell F (1990) Stress, coping style, and problem solving ability among eating-disordered inpatients. Journal of Clinical Psychology 46: 592-599.

Vaismoradi M, Salsali M, Marck P (2011) Patient safety: Nursing students' perspective and the role of nursing education to provide safe care. International Nursing Reviews 58: 434-442

Wallace L, Bourke MP, Tormoehlen LJ, Poe-Greskamp MV (2015) Perceptions of clinical stress in baccalaureate nursing students. International Journal of Nursing Education 12(1): 91-98.

World Health Organization (WHO) (2010) WHO patient safety. World Health Organization. Retrieved from http://www.who.int/topics/patient_safety/en/. 
